\title{
Transforaminal Lumbar Puncture: An Alternative Technique in Patients with Challenging Access
}

\author{
(DD.R. Nascene, (D) C. Ozutemiz, (D) H. Estby, (D)A.M. McKinney, and (D).B. Rykken
}

\begin{abstract}
SUMMARY: Interlaminar lumbar puncture and cervical puncture may not be ideal in all circumstances. Recently, we have used a transforaminal approach in selected situations. Between May 2016 and December 2017, twenty-six transforaminal lumbar punctures were performed in 9 patients (25 CT-guided, 1 fluoroscopy-guided). Seven had spinal muscular atrophy and were referred for intrathecal nusinersen administration. In 2, CT myelography was performed via transforaminal lumbar puncture. The lumbar posterior elements were completely fused in 8, and there was an overlying abscess in 1. The L1-2 level was used in 2; the L2-3 level, in 10; the L3-4 level, in 12; and the L4-5 level, in 2 procedures. Post-lumbar puncture headache was observed on 4 occasions, which resolved without blood patching. One patient felt heat and pain at the injection site that resolved spontaneously within hours. One patient had radicular pain that resolved with conservative treatment. Transforaminal lumbar puncture may become an effective alternative to classic interlaminar lumbar puncture or cervical puncture.
\end{abstract}

ABBREVIATIONS: $L P=$ lumbar puncture; SMA = spinal muscular atrophy; SMN = survival motor neuron; TFLP = transforaminal lumbar puncture

$\mathbf{F}$ luoroscopy-guided lumbar puncture (LP) is a routine procedure performed by radiologists. While typically performed for CSF laboratory testing, other indications include CSF opening pressure measurement, myelography, cisternography, intrathecal drug administration, and therapeutic CSF drainage. ${ }^{1-3}$ LP via an interlaminar approach is a safe and ubiquitous method to access the intrathecal compartment. However, interlaminar LP may not be feasible in certain complex conditions, such as complete fusion of the posterior elements or in the presence of an infectious process in the subcutaneous tissues of the low back along the planned needle path. In those situations, C1-2 cervical puncture or suboccipital cisternal puncture under CT or fluoroscopy guidance is a possible alternative to obtain access. ${ }^{4,5}$ However, some institutions perform such procedures infrequently, and not all radiologists may be comfortable with these procedures, especially given the possible severity of complications. In a 2009 survey, $14 \%$ of respondents described $<1$ cervical puncture for myelography on average per year in their neuroradiology fellowship program. ${ }^{6} \mathrm{~A}$ 1990 survey of neuroradiologists reported 7 cases of paraparesis, 7

Received December 9, 2017; accepted after revision January 24, 2018.

From the Department of Radiology (D.R.N., C.O., A.M.M., J.B.R.), Neuroradiology Section, University of Minnesota, Minneapolis, Minnesota; and University of Minnesota Medical School (H.E.), Minneapolis, Minnesota.

Please address correspondence to Can Ozutemiz, MD, Department of Radiology, University of Minnesota, MMC 292, 420 Delaware St SE, Minneapolis, MN 55455;

e-mail: ozutemiz@umn.edu

http://dx.doi.org/10.3174/ajnr.A5596 cases of quadriparesis, and 1 death attributed to cervical myelography. ${ }^{7}$ The same survey reported 16 cases of injection of contrast into the spinal cord, 5 cases of spinal cord puncture, and 3 cases of vertebral artery injury. ${ }^{7}$

Despite the risk of these feared complications, cervical puncture is considered a safe procedure in experienced hands. ${ }^{4,6,8}$ If available, preprocedural imaging should be reviewed to confirm the patency of the posterior spinal canal and to evaluate the position of the vertebral arteries. Unfortunately, some patients are not good candidates for interlaminar LP and have challenging cervical anatomy (eg, prior fusion procedure, spinal muscular atrophy [SMA], or ankylosing spondylitis). Therefore, cervical puncture may not be a viable option, even by the most experienced radiologists.

SMA is an autosomal recessive inherited disorder, with loss of both copies of the SMN1 gene located on the long arm of chromosome 5 (5q), which encodes survival motor neuron (SMN), a protein necessary for motor neuron survival. SMA type 1 (Werdnig-Hoffmann disease) presents in early infancy and is the most severe form, often leading to death before 2 years of age. SMA types 2 and 3 are less severe, with SMA2 presenting later in the first year of life, and SMA3, later in childhood but sometimes in adulthood. All types of SMA cause progressive muscle wasting, frequently causing neuromuscular scoliosis and thoracic insufficiency syndrome. Severe scoliosis often requires posterior spinal fusion procedures for proper diaphragm function, ${ }^{9}$ which may result in complete osseous interlaminar fusion that precludes interlaminar LP. 


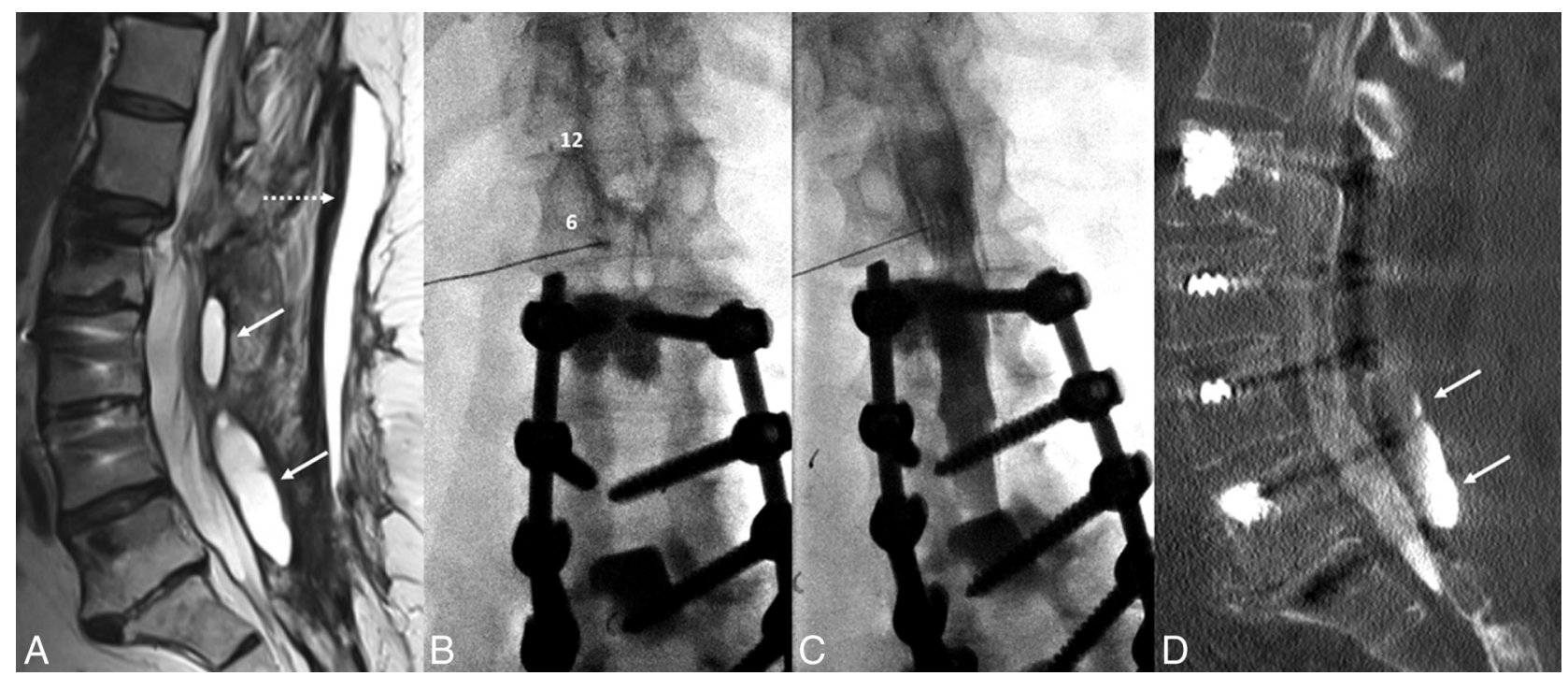

FIG 1. A 67-year-old woman with a history of multiple spinal fusions presented with newly worsening low back and radicular leg pain (case 1). Sagittal T2-weighted MR imaging $(A)$ shows 2 paraspinous fluid collections (white arrows) within the deep paraspinal musculature and a midline subcutaneous fluid collection (dashed arrow) with rim enhancement on postcontrast series (not shown). B, Anteroposterior fluoroscopy image of myelography with TFLP. The needle tip is beyond the medial edge of the pedicle at the 5 o'clock position (relative to the pedicle). Note the position of the needle inferior to the expected location of the exiting nerve root and dorsal root ganglion. C, Oblique fluoroscopy image shows contrast extending into the intrathecal space after injection through the left L1-2 foramen. $D$, CT myelogram demonstrates the inferiorly located cystic collection filled with contrast, confirming a pseudomeningocele (arrows).

Recently, several patients with SMA have been referred to our institution for intrathecal nusinersen (Spinraza) injection. Nusinersen is a newly developed antisense oligonucleotide drug that alters the splicing of SMN2 messenger RNA. The SMN2 gene is paralogous to SMN1 and is usually present in patients with SMA. Both genes can yield the SMN protein. However, the version of the SMN protein encoded by native SMN2 is rapidly degraded and is not sufficient to prevent motor neuron loss. In the presence of nusinersen, the altered splicing of SMN2 leads to a more durable and long-lived protein product that, in turn, increases the amount of functional SMN protein. ${ }^{10,11}$ The treatment course requires 3 loading doses separated by 2 weeks and a fourth injection 1 month after the third loading dose, followed by repeat injections every 4 months.

There are several circumstances in which there may be a need for an alternative route into the thecal sac. Recently, we have used a transforaminal approach for LP, using either fluoroscopy or CT guidance. To our knowledge, this method is not well-described in the literature. Our purpose is to describe this alternative technique and share our initial experience.

\section{CASE SERIES}

\section{Case Selection}

This retrospective case series was institutional review board-approved. Between March 2016 and November 2017, twenty-six transforaminal lumbar puncture (TFLP) procedures were performed in 9 different patients, 25 with CT and 1 with fluoroscopic guidance. Informed consent was obtained from each patient. CT-guided procedures were performed with the Sensation 64 scanner (Siemens, Erlangen, Germany), and fluoroscopyguided procedures were performed with the OEC 9900 Mobile C-arm (GE Healthcare, Milwaukee, Wisconsin). Patient characteristics including age, sex, body mass index, and postproce- dural complications were obtained from the electronic medical record. Used modality, puncture level, and needle length were also obtained. Of note, all patients receiving nusinersen were called by nursing staff after each procedure to identify complications.

\section{RESULTS}

Twenty-six TFLPs were performed in 7 female and 2 male patients with $100 \%$ technical success. The mean age was 39.6 years (range, 31-68 years). The mean body mass index was 21.9 (range, 12.6-40), with the body mass index not available for 1 patient. Seven patients with SMA (6 with SMA type 2 and 1 with SMA type 3) were referred for intrathecal nusinersen administration. In 2 patients, the indication for TFLP was postoperative CT myelography.

All procedures were performed using 22-ga Quincke needles (Becton-Dickinson, Washington, DC), 3.5 inch in 10 procedures, 5 inch in 14, and 7 inch in 2. For TFLP, the L1-2 spinal level was used in 2 procedures; the L2-3 level, in 10; the L3-4 level, in 12; and the L4-5 level, in 2. In cases with CT-fluoroscopy guidance, routinely, kilovolt(peak) and milliampere-second were set as 80 and 50, respectively. In cases in which the needle tip was not seen ideally due to streak artifacts, the kilovolt(peak) was increased to 100. The total dose-length product varied between 22 and 158 with a mean of $57.5 \pm 35.3 \mathrm{mGy} \times \mathrm{cm}$. Slice thickness was either 3 or $5 \mathrm{~mm}$.

\section{Case 1}

A 67-year-old woman with a history of multiple previous spinal fusion procedures presented with newly worsening low back and radicular leg pain 6 months after lumbar fusion and laminectomy. Spine MRI showed 2 paraspinous fluid collections and a large midline subcutaneous fluid collection, all of which exhibited rim enhancement (Fig 1). With clinical suspicion of abscess versus 


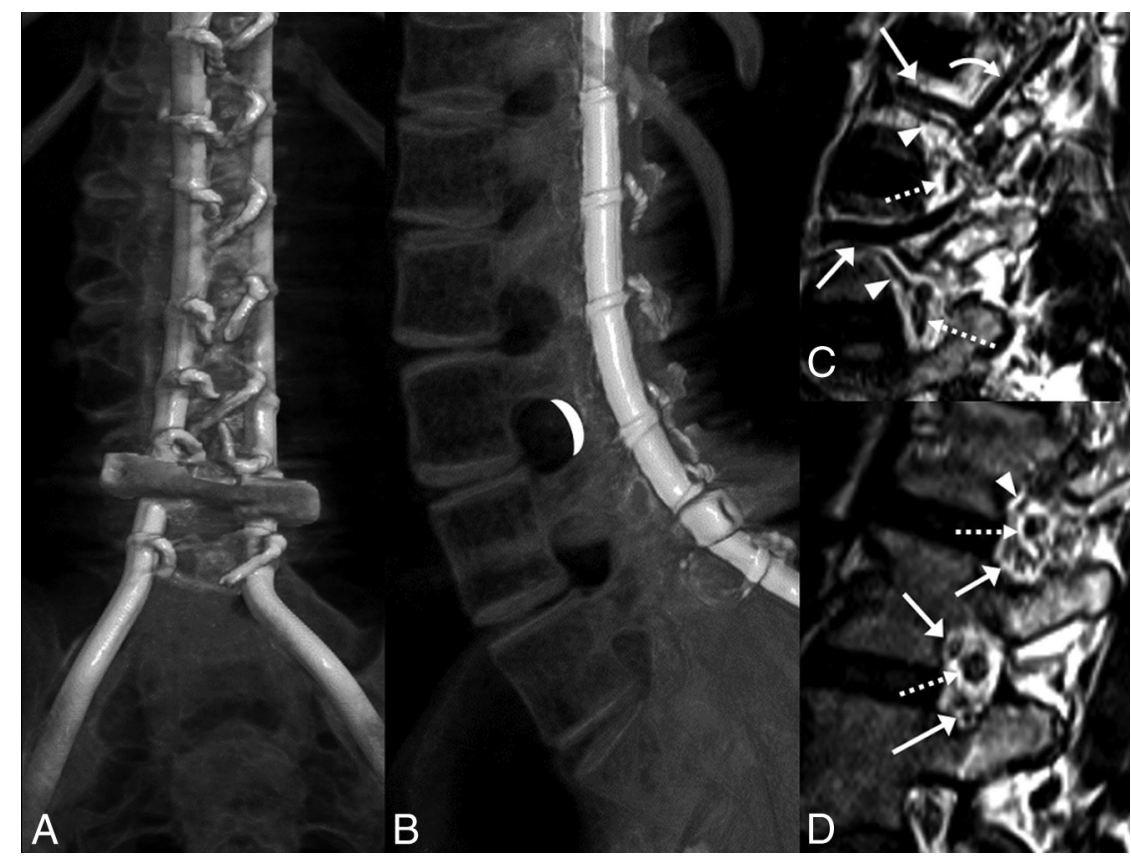

FIG 2. $A$ and $B, C T$ volumetric rendering of a patient with SMA2 demonstrates extensive posterior spinal fusion hardware and complete osseous interlaminar fusion without any access for a classic interlaminar LP. Note the widely patent neural foramina. The white crescent represents the target for TFLP. $C$ and D, Sagittal 3D volumetric T2-weighted images of a healthy person obtained with 3T MR imaging. C, Image obtained slightly lateral to the neural foramen. $D$, Image obtained at the foramen. Flow voids of the lumbar arteries (arrowheads) and larger caliber lumbar veins (arrows) are seen in the anterior superior aspect of the foramen. A branching ascending lumbar vein is seen coursing toward a higher level neural foramen (curved arrow). More venous structures are seen in the inferior aspect of the foramen (arrows in D). Exiting nerve roots are shown within the center of the foramen (dashed arrows).

pseudomeningocele communicating with the CSF, percutaneous aspiration of the fluid collections and CT myelography were requested to determine the etiology of the pain and evaluate the provisional diagnosis of pseudomeningocele. Both procedures were scheduled on the same day at the request of the ordering surgeon, given the patient's social and transportation difficulties.

The patient was placed in a prone position under moderate sedation. The initial intent was to drain enough of the midline fluid to allow a steep oblique interlaminar approach for myelography using a combination of fluoroscopy and sonography. After $46 \mathrm{~mL}$ of fluid was drained, sonography showed residual fluid that, if traversed, could potentially contaminate the intrathecal compartment. Despite sedation, the patient was too agitated to safely undergo a C1-2 puncture, and rescheduling with the patient under general anesthesia was not desirable. As the back was already exposed and appropriately positioned, we elected to attempt TFLP. After re-prepping, a 5-inch 22-ga spinal needle was used to puncture the thecal sac at a $35^{\circ}$ oblique transforaminal, infraneural approach at the L1-2 level using C-arm fluoroscopy, more oblique than usual for a transforaminal epidural injection (Fig 1). This approach was selected to minimize the risk of injury to the dorsal root ganglion, guiding the needle posterior and inferior to the known location of the ganglion seen by previous MR imaging and inferior to the conus medullaris. The patient tolerated the procedure well without any immediate complication.

\section{Case 2}

A 58-year-old man with a history of ankylosing spondylitis, morbid obesity, exaggerated thoracolumbar kyphosis, and T11 fracture had an extensive posterior surgical fusion from T4 through the pelvis. Following the operation, he developed bilateral quadriceps femoris weakness concerning for nerve compression, and an MR imaging was performed. Due to extensive metallic susceptibility, MR imaging findings were inadequate and a CT myelogram was planned. Due to ankylosing spondylitis, there was near-complete fusion of the posterior elements. An interlaminar lumbar puncture was attempted through a small L5-S1 laminectomy defect but was unsuccessful. A cervical puncture was also not ideal due to the patient's extreme cervical kyphosis secondary to ankylosing spondylitis. Therefore, a right TFLP was performed at L1-2 under CT guidance with a slightly oblique prone position using a 7 inch-long Quincke needle, with uncomplicated myelography.

\section{Cases 3 through 9}

Six patients with SMA type 2 and 1 with SMA type 3 were referred for intrathecal nusinersen injection. All patients with SMA in this TFLP series had undergone extensive fusion procedures from the thoracic spine through the pelvis.

Preprocedural evaluation of lumbar spine radiographs and CT studies revealed extensive spinal fusion hardware and resultant complete osseous interlaminar fusion without any access for classic interlaminar LP (Fig 2). Alternative surgical options discussed with the patients included Ommaya reservoir and lumbar shunt placement (after drilling through the fused laminae). After we discussed the risks and benefits of the different approaches, these 7 patients with SMA decided to proceed with TFLP.

All procedures were successfully performed under CT guidance with the patient in the decubitus position without any need for sedation or general anesthesia.

\section{Complications}

Patient 3 experienced a post-LP headache after the second nusinersen injection, which resolved after 5 days with conservative management. Patient 4 had a post-LP headache after the first procedure, which resolved on the same day. This same patient experienced heat and pain at the injection site after the second injection, which resolved spontaneously within hours. Patient 6 had radicular pain after the third injection corresponding to the injection site, leading her to seek treatment in the emergency department. CT did not show any complications, and the pain resolved with conservative treatment. Patient 9 had post-LP headaches after 2 injections, both of which resolved the same day. In total, post-LP headache was observed following 4 procedures 


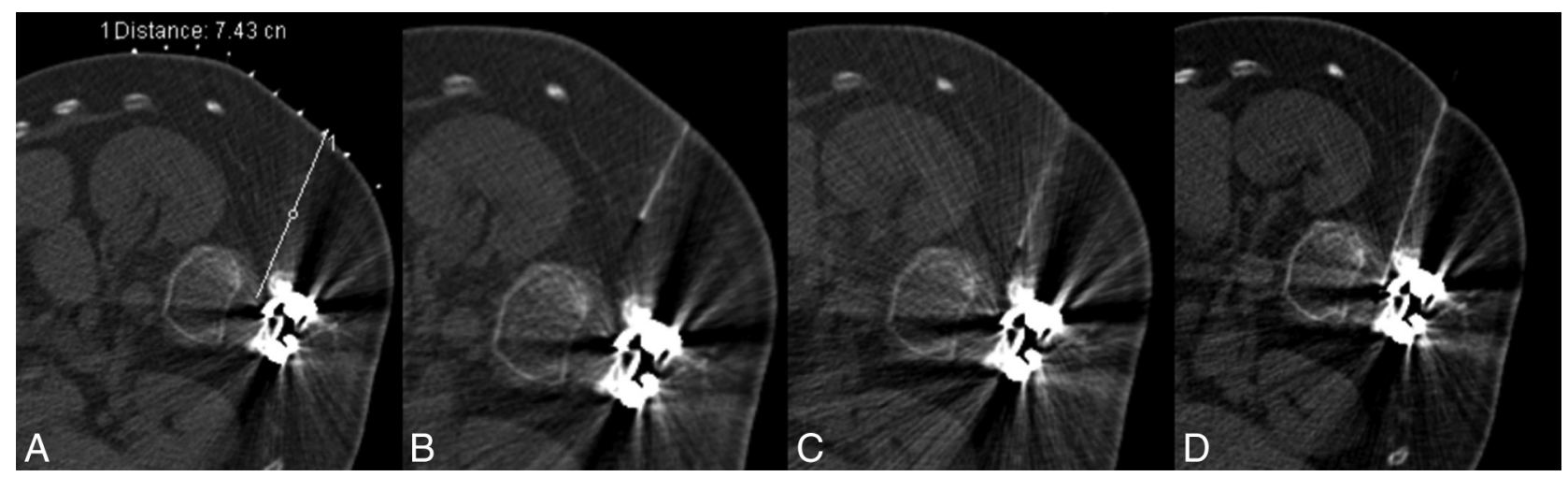

FIG 3. A 32 -year-old man with SMA2 (case 5). A, Planning scout CT image with grid placement, obtained in the lateral decubitus position. $B$, Initial CT fluoroscopy image shows the needle more anteriorly oriented than desired. $C$, With basic needle manipulations, the needle is directed more posteriorly. D, Technically successful TFLP with the needle positioned immediately anterior to the facet.

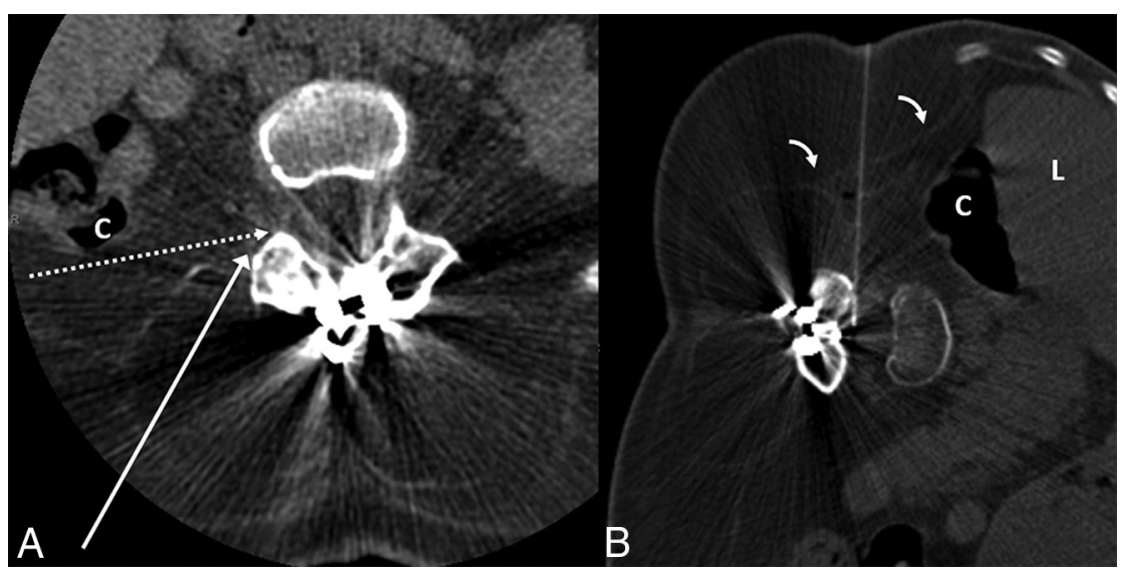

FIG 4. A 36-year-old woman with SMA2 (case 6). A, Preprocedural CT obtained in supine position at the level of L3-4 demonstrates extensive muscle atrophy. The long white arrow shows the normal needle trajectory for a transforaminal epidural steroid injection. The dashed white arrow indicates the needle trajectory for TFLP. Note that while supine, the posterior margin of the ascending colon (C) is along the proposed needle trajectory. B, CT fluoroscopy image during TFLP obtained with the patient in the left lateral decubitus position. The needle is advanced into the thecal sac with an angle slightly $>90^{\circ}$, just anterior to the facet. Note the anterior displacement of the liver $(L)$ and ascending colon $(C)$ in the decubitus position, providing a safer approach. Of note, the thin transversalis fascia (bent arrows) is well-visualized.

(15\%), affecting 3 different patients. Only 1 of these 4 headaches lasted longer than 1 day, and all resolved with conservative management.

TFLP has been performed in our department since March 2016, and no long-term complications have been observed.

\section{DISCUSSION}

\section{Anatomy}

When performing TFLP, the proceduralist should be familiar with the anatomic location of the exiting nerve root, the radiculomedullary arteries, and, potentially, the artery of Adamkiewicz. The radiculomedullary branches are in the anterosuperior aspect of the foramen, while the ganglion and exiting nerve root are in the midportion of the foramen (Fig 2). Only smaller branch arteries and veins are found in the posterior aspect of the neural foramen. ${ }^{12}$ In our method of TFLP, the needle is passed through the posterior portion of the foramen into the spinal canal (Figs 2-4) to minimize the risk of neurovascular injury. Thus, the operator should be proficient with transforaminal procedures as a prerequisite to TFLP.

\section{Technique}

Prior lumbar imaging is evaluated for each patient to select the safest level and side for the procedure based on the position of the conus medullaris, patency of the neural foramen, and positioning of the adjacent organs. Patients are positioned in the lateral decubitus position. In patients with scoliosis, the convex side is positioned upward. If CT is used for the procedure, an initial low-dose scout CT $(80 \mathrm{kVp}, 50-80 \mathrm{mAs})$ is performed with grid placement over the presumed injection side. Even with extensive hardware, the low-dose technique provides adequate visualization of the foramina. The planning CT is evaluated to confirm safety, and the shortest approach to the posterior neural foramen is selected, often necessitating a nearly $90^{\circ}$ approach. The overlying skin is prepped, draped, and anesthetized with $1 \%$ lidocaine via a 27 -ga needle or J-tip. A 22 -ga Quincke needle is advanced toward the posterior aspect of the neural foramen under imaging guidance (Figs 3 and 4). It is reported that during LP, orienting the cutting edge of the needle parallel to the longitudinally oriented dural fibers reduces the likelihood of CSF leaks. $^{13,14}$

Due to scoliosis and altered body wall anatomy, retroperitoneal organs such as the kidney and colon may be located more posteriorly than anticipated, especially as depicted by supine cross-sectional imaging. However, our experience has taught us that the decubitus position often shifts these organs anteriorly, allowing needle trajectories that did not appear feasible on the planning supine imaging (Fig 4).

While the procedure is relatively pain-free following skin anesthesia, we have noted that some patients feel sharp pain as the needle crosses the muscular portion of the posterolateral abdominal wall (Fig 4). We now advance the needle just to the transversalis fascia and administer additional lidocaine before advancing further.

Recently, Weaver et $\mathrm{al}^{15}$ reported their initial experience with 
TFLP using conebeam CT for 15 transforaminal nusinersen injections in 4 adolescents with SMA (13-17 years of age). Three of their patients required general anesthesia, and 1 patient required mild sedation. In our experience, TFLP under CT guidance can be performed with any CT, ideally with CT fluoroscopy. Sedation was not necessary for the adult patients in our study. While Weaver et al did not discuss the needle positioning in detail, we believe that targeting the posterior neural foramen, preferably posteroinferiorly, will produce the fewest complications.

\section{Safety}

Lumbar transforaminal procedures are safe and effective for several indications. Transforaminal lumbar epidural steroid injections have been used commonly and safely with good clinical outcomes. ${ }^{16,17}$ A small number of case reports describe rare but serious adverse events, including spinal cord infarction and paraplegia following transforaminal epidural steroid injection. ${ }^{18-20} \mathrm{~A}$ recent multi-institutional study revealed low rates of serious adverse events in nearly 14,000 transforaminal epidural procedures, without any instance of hemorrhage, infection, or neurologic complication. Less serious effects such as increased pain, central steroid effect, and allergic reaction occurred in $<5 \%$ of cases, with no statistically significant difference between interlaminar and transforaminal epidural steroid injections. ${ }^{21}$ Recently, CT-guided transforaminal blood patch has successfully treated ventral CSF leaks. $^{22}$

The most common complication of LP is post-LP headache, which typically occurs or worsens in the upright position and improves or resolves with lying down. ${ }^{23}$ Younger age and female sex have been identified as significant risk factors, and these patients are more likely to receive an epidural blood patch. ${ }^{23,24}$ The incidence of post-LP headache varies between $2.2 \%$ and $32 \%$ with different techniques and instrumentation. ${ }^{23-25}$ Rodriguez et $\mathrm{al}^{24}$ reported post-LP headache in $2.2 \%$ of 2141 patients who underwent fluoroscopy-guided lumbar puncture using either a 22- or 25-ga Quincke needle.

In the study by Haché et al, ${ }^{11} 73$ classic interlaminar LPs were performed in 28 patients with SMA for nusinersen injection. They reported 17 (23\%) headache events, 9 with uncomplicated headache and 8 with post-lumbar puncture syndrome, consisting of headache with or without vomiting. Seven (10\%) sought medical treatment and $1(1.4 \%)$ required blood patch. In our small case series, the incidence of post-LP headache was $15 \%$, and $1(3.8 \%)$ sought additional medical treatment but was managed conservatively. No blood patch procedures were performed. While our post-LP headache rate was higher compared with the study of Rodriguez et $\mathrm{al}^{24}$ (which contained a higher number of healthy patients), our complication rate with TFLP was lower than that for interlaminar LP compared with the study by Haché et al (containing only patients with SMA). ${ }^{11,24}$

While there is evidence that cutting needles, such as the Quincke needles used in our study, lead to a higher rate of post-LP headache, the rate of headache requiring an epidural blood patch is not significantly different between the Quincke needle and nontraumatic needles. ${ }^{26,27}$ The study by Rodriguez et $\mathrm{al}^{24}$ demonstrated that it is possible to obtain a very low rate of headache despite using Quincke needles. In addition, studies have shown a high crossover rate from nontraumatic needles to Quincke needles, with some operators considering nontraumatic needles more difficult. ${ }^{28,29}$ While atraumatic needles are associated with a lower risk of headache from an interlaminar approach, it is premature to conclude that atraumatic needles will also yield a lower headache rate with TFLP. To our knowledge, our study and the study of Weaver et al ${ }^{15}$ provide the only information on this technique, and both used Quinke needles. We continue to use Quincke needles, which we can more precisely position into the posterior neural foramen. Further study will be required to compare the success rates and safety profiles of the different needle types with TFLP.

While we performed our first procedure under fluoroscopic guidance, all subsequent cases were performed with CT. With CT, the posterior portion of the neural foramen can be targeted from a lateral approach without fear of injuring the colon or kidney. Obliquity of $<90^{\circ}$ may result in the needle entering the anterolateral portion of the foramen, which, in our opinion, should be avoided if possible. Given the body wall changes in many of our patients with SMA, we elected to proceed with CT to minimize organ injury. We believe that TFLP will prove safe by fluoroscopy and, with consistent decubitus positioning, should be achievable. As a next step, we plan to incorporate sonography as an adjunct to fluoroscopy to confirm the safety of the needle path during future procedures.

Our study has several limitations. First, this is a retrospective evaluation of a method that has been used in only a few patients. Although we have not encountered any long-term complications, it has only been 18 months since our first TFLP. Additional time and further studies will be needed to characterize any long-term risks. Second, our study is largely based on our experience in patients with SMA with spinal fusion hardware and interlaminar osseous fusion. We believe that fluoroscopy-guided TFLP will likely prove feasible in patients with more typical anatomy, with CT-guided TFLP reserved for patients with more challenging anatomy, such as those with SMA, ankylosing spondylitis, or scoliosis. In summary, we believe that TFLP will prove an acceptable alternative to $\mathrm{C} 1-2$ puncture.

\section{CONCLUSIONS}

Although more research will be necessary to determine the relative safety of TFLP, we believe that the transforaminal approach will prove a viable alternative in patients with contraindications to classic interlaminar lumbar puncture or cervical puncture. In addition, decubitus positioning may uncover transforaminal approaches that do not appear possible when reviewing preprocedural supine imaging.

\section{REFERENCES}

1. Abel AS, Brace JR, McKinney AM, et al. Practice patterns and opening pressure measurements using fluoroscopically guided lumbar puncture. AJNR Am J Neuroradiol 2012;33:823-25 CrossRef Medline

2. Cauley KA. Fluoroscopically guided lumbar puncture. AJR Am J Roentgenol 2015;205:W442-50 CrossRef Medline

3. Ozdoba C, Gralla J, Rieke A, et al. Myelography in the age of MRI: why we do it, and how we do it. Radiol Res Pract 2011;2011:329017 CrossRef Medline

4. Gibbs WN, Skalski MR, Kim PE, et al. C1-2 puncture: a safe, effica- 
cious, and potentially underused technique. Neurographics 2017;7: 1-8 CrossRef

5. Pomerantz SR, Buchbinder B, Hirsch JA. Suboccipital puncture of the cisterna magna under CT-guidance with intravenous enhancement in order to circumvent anomalous course of posterior inferior cerebellar artery (PICA). In: Proceedings of the American Society of Spine Radiology Annual Symposium, San Juan, Puerto Rico. February $24-27,2005$

6. Yousem DM, Gujar SK. Are C1-2 punctures for routine cervical myelography below the standard of care? AJNR Am J Neuroradiol 2009;30:1360-63 CrossRef Medline

7. Robertson HJ, Smith RD. Cervical myelography: survey of modes of practice and major complications. Radiology 1990;174:79-83 CrossRef Medline

8. Heinz ER. Development of the $\mathrm{C} 1-\mathrm{C} 2$ puncture in neuroradiology: a historical note. AJNR Am J Neuroradiol 2005;26:5-6 Medline

9. Kolb SJ, Kissel JT. Spinal muscular atrophy. Neurol Clin 2015;33: 831-46 CrossRef Medline

10. Corey DR. Nusinersen, an antisense oligonucleotide drug for spinal muscular atrophy. Nat Neurosci 2017;20:497-99 CrossRef Medline

11. Haché M, Swoboda KJ, Sethna N, et al. Intrathecal injections in children with spinal muscular atrophy: nusinersen clinical trial experience. J Child Neurol 2016;31:899-906 CrossRef Medline

12. Demondion X, Lefebvre G, Fisch O, et al. Radiographic anatomy of the intervertebral cervical and lumbar foramina (vessels and variants). Diagn Interv Imaging 2012;93:690-97 CrossRef Medline

13. Flaatten $\mathrm{H}$, Thorsen $\mathrm{T}$, Askeland $\mathrm{B}$, et al. Puncture technique and postural postdural puncture headache: a randomised, doubleblind study comparing transverse and parallel puncture. Acta Anaesthesiol Scand 1998;42:1209-14 CrossRef Medline

14. Lybecker H, Moller JT, May O, et al. Incidence and prediction of postdural puncture headache: a prospective study of 1021 spinal anesthesias. Anesth Analg 1990;70:389-94 Medline

15. Weaver JJ, Natarajan N, Shaw DWW, et al. Transforaminal intrathecal delivery of nusinersen using cone-beam computed tomography for children with spinal muscular atrophy and extensive surgical instrumentation: early results of technical success and safety. Pediatr Radiol 2018;48:392-97 CrossRef Medline

16. Manchikanti L, Kaye AD, Manchikanti K, et al. Efficacy of epidural injections in the treatment of lumbar central spinal stenosis: a systematic review. Anesth Pain Med 2015;5:e23139 CrossRef Medline

17. Shim E, Lee JW, Lee E, et al. Fluoroscopically guided epidural injec- tions of the cervical and lumbar spine. Radiographics 2017;37: 537-61 CrossRef Medline

18. Huntoon MA, Martin DP. Paralysis after transforaminal epidural injection and previous spinal surgery. Reg Anesth Pain Med 2004;29: 494-95 Medline

19. Somayaji HS, Saifuddin A, Casey AT, et al. Spinal cord infarction following therapeutic computed tomography-guided left L2 nerve root injection. Spine 2005;30:E106-08 CrossRef Medline

20. Karaman H, Kavak GO, Tüfek A, et al. The complications of transforaminal lumbar epidural steroid injections. Spine 2011;36:E819-24 CrossRef Medline

21. El-Yahchouchi CA, Plastaras CT, Maus TP, et al. Adverse event rates associated with transforaminal and interlaminar epidural steroid injections: a multi-institutional study. Pain Med 2016;17:239-49 CrossRef Medline

22. Amrhein TJ, Befera NT, Gray L, et al. CT fluoroscopy-guided blood patching of ventral CSF leaks by direct needle placement in the ventral epidural space using a transforaminal approach. AJNR Am J Neuroradiol 2016;37:1951-56 CrossRef Medline

23. Evans RW, Armon C, Frohman EM, et al. Assessment: prevention of post-lumbar puncture headaches: report of the therapeutics and technology assessment subcommittee of the American Academy of Neurology. Neurology 2000;55:909-14 CrossRef Medline

24. Rodriguez D, Branstetter BF 4th, Agarwal V, et al. Journal club: incidence of complications following fluoroscopically guided lumbar punctures and myelograms. AJR Am J Roentgenol 2016;206:20-25 CrossRef Medline

25. Armon C, Evans RW. Addendum to assessment: prevention of postlumbar puncture headaches-report of the Therapeutics and Technology Assessment Subcommittee of the American Academy of Neurology. Neurology 2005;65:510-12 CrossRef Medline

26. Lavi R, Yarnitsky D, Rowe JM, et al. Standard vs atraumatic Whitacre needle for diagnostic lumbar puncture: a randomized trial. Neurology 2006;67:1492-94 CrossRef Medline

27. Strupp M, Schueler O, Straube A, et al. "Atraumatic" Sprotte needle reduces the incidence of post-lumbar puncture headaches. Neurology 2001;57:2310-12 CrossRef Medline

28. Castrillo A, Tabernero C, Garcia-Olmos LM, et al. Postdural puncture headache: impact of needle type, a randomized trial. Spine J 2015;15:1571-76 CrossRef Medline

29. Peterman SB. Postmyelography headache rates with Whitacre versus Quincke 22-gauge spinal needles. Radiology 1996;200:771-78 CrossRef Medline 